\title{
The impact of newborn on adult mice: Open-field behavior along with pullus index
}

\author{
S. BÉATRICE M. KVIST, RITVA-KAJSA SELANDER, and VAPPU VIEMERÖ \\ Abo Akademi University, Turku, Finland
}

\begin{abstract}
The open-field- $(\mathrm{OF})$ dependent parameters ambulation, thigmotactical wall-seeking, radial latency, retrieving and pullus index were tested in both nulliparous and primiparous females as well as in unmated and mated males of the Swiss albino strain. The mice were housed under separate conditions and recorded in the absence as well as the presence of a biological or unrelated 1-day old pup placed either in the center or by the wall in a familiar OF. The results revealed an ambulatory response of recognition of the newborn's genetic origin in single-caged females and family-housed males. The young's initial OF location was decisive for adult $O F$ behavior. In general, housing conditions affected family-caged primiparous females most. The pullus index or attraction toward pups reflected a need to retrieve the young. Simultaneous recordings of changes in two or more OF-dependent parameters made an integrate whole of the results.
\end{abstract}

The impetus to conduct open-field (OF) experiments on the influence of newborn pups on adult mice that may or may not be in a maternal physiological or psychological state but that are housed in differing conditions preventing or enhancing contact with a gestational or delivering female or her litter came from our earlier study (Kvist \& Selander, 1994). We indicated increased OF ambulatory and wall-seeking behavior in singly caged primiparous mice in the presence of their 1- or 2-day-old pups. The importance of the pups' being 1 or 2 days old in eliciting adult mouse vigilance has been stressed by Noirot (1964a). Experiments on rodent parental care were previously conducted inside or in the vicinity of the nest; at least one of the test animals was in a secure place, which would not provoke unpracticed responses (Csermely \& Mainardi, 1983). An unsheltered OF shares attributes with a seminatural environment, which, according to Brown (1993), allows the ideal setting for the researcher to clearly observe responses of the type in which we are interested. In unfamiliar surroundings, a change of an adult's inclination to react with a discriminating response to biological or unrelated young on the one hand, or, on the other, to protect whatever needs protection in a functionally adaptive way was our present focus.

Background for the present research was provided by studies on maternal OF behavior (Ader \& Belfer, 1962; Akuta, 1979; Bauer, 1980; Lagerspetz \& Heino, 1970; Lassalle, Bulman-Fleming, \& Wahlsten, 1991; Mainardi, Mainardi, Favoriti, \& Pasquali, 1976; Ward, 1980). These studies did not concentrate on the importance of housing conditions; studies on paternal OF behavior did not do so

Correspondence concerning this article should be addressed to S. B. M. Kvist, Department of Psychology, Åbo Akademi University, Nunnegatan 4, FIN-20500 Turku, Finland (e-mail: bekvist@finabo). either. The latter reports are mainly preoccupied with the significance of the absence or presence of the male in the nest on the development of the young (Bradley, 1969; Csermely, 1980; Elwood \& Broom, 1978; Fullerton \& Cowley, 1971; Hayashi \& Kimura, 1978; McCarty \& Southwick, 1977; Mugford \& Nowell, 1972). Nevertheless, according to Brown (1993), males of many species are, under certain conditions, known to engage in pup-related activities, a fact that compelled investigators (e.g., BrouetteLahlou, Vernet-Maury, \& Chanel, 1991) to identify the attractants of a pup that are sufficiently effective to evoke parental care to ensure its survival. Depending on housing conditions and the recipient's sensitivity to the attractants of or capacity to become psychologically aroused by the newborn, both parturient and nulliparous females, together with males, may take over or adopt the young (Csermely \& Mainardi, 1983; Noirot, 1964a, 1964b). Pup-dependent cues may even block cannibalistic behavior.

This particular report was aimed at recording pup-induced psychological arousal reflected as OF motor discharge. Psychological arousal refers to a mental state causing changes in one's behavior in a notable manner, presently recorded as alterations in OF-dependent parameters. On the basis of our earlier reasearch (Kvist \& Selander, 1994), the following can be asserted: (1) Pup-induced arousal is reflected in parental OF ambulation, wall-seeking behavior, radial latency, and retrieval. (2) Adult mice do not discriminate between biological or unrelated 1- or 2-day-old young in a behaviorally observable manner (Csermely \& Mainardi, 1983; Noirot, 1964a), yet both of the sexes do not necessarily display identical pup-induced OF responses. (3) Family housing alters pup-induced adult OF responses. (4) The newborn's OF position is likely to affect paternal and virginal female responses, since it affects primiparous OF behavior (Kvist \& Selander, 1994). (5) A behavioral estimate of an adult's pup-induced psychological arousal or attraction toward a newborn is introduced. 


\section{METHOD}

\section{Subjects}

A total of 46 adult mice ( 24 females and 22 males) from an outbred Swiss albino stock were used. All of the mice were bred and reared in the laboratory of the Department of Psychology at Abo Akademi University. The adult animals were weaned at the age of 4 weeks and were run in the experiments from the age of 6.5 months and mated at approximately 7 months. Their litter sizes were 6.5 $(S D=2.5)$ pups per dam on average. The adult mice were recorded for a period of 39 days and were tested once a day. The testing was generally performed from 7 to $10 \mathrm{a} . \mathrm{m}$. but the pup test (Table 1) was recorded twice a day for the randomized adult mice from 7 to $10 \mathrm{a} . \mathrm{m}$. and from 5 to 8 p.m. in order to accomplish the recordings before the young grew older than 2 days (Noirot, 1964a; Wimer \& Fuller, 1966). The experimental design is presented in Table 1.

\section{Housing Conditions}

From the beginning of experimentation, the adult mice were individually housed in wire-topped laboratory aluminum cages measuring $15.5 \times 15.5 \times 12.0 \mathrm{~cm}$. After mating on the 7 th day of experimentation, females and males cohabited for 14 days. Females gave birth on approximately the 27 th day of experimentation. Seven couples remained in the cage throughout the experiment. These animals were labeled family females and family males. After 2 weeks, eight couples were separated, and each of the male partners was transferred to an empty cage of the same size until the end of the experiment. These animals were designated single females and single males, respectively. Nine singly caged virgin females and 10 unmated males served as reference mice. Three unmated males treated the litter as food and were therefore excluded. All animals were maintained in a noiseless breeding room on a 12:12-h light:dark cycle, with lights on at 7 a.m. The room temperature was approximately $22^{\circ} \mathrm{C}$, and the humidity, $45 \%$. Standard laboratory animal food pellets and tap water were available ad lib.

\section{Apparatus \\ The OF (Figure 1) consisted of a circular, flat, white, wooden arena $(40 \mathrm{~cm}$ in diameter) with a $20-\mathrm{cm}$-high wall of flat, white iron plat- ing. The field was marked with thin black lines to delineate three concentric circles. These were in turn divided by 12 lines radiating from the center. The floor was thus subdivided into a total of 19 par- titions, in order to aid the marking of the track of the animal on a sim- ilarly divided map and provide raw scores for calculation of ambu- lation, wall-seeking, retrieving, and pullus index or attraction to pups. The arena was cleaned with a wet paper towel and dried with another between successive recordings, which is considered adequate to pre-}

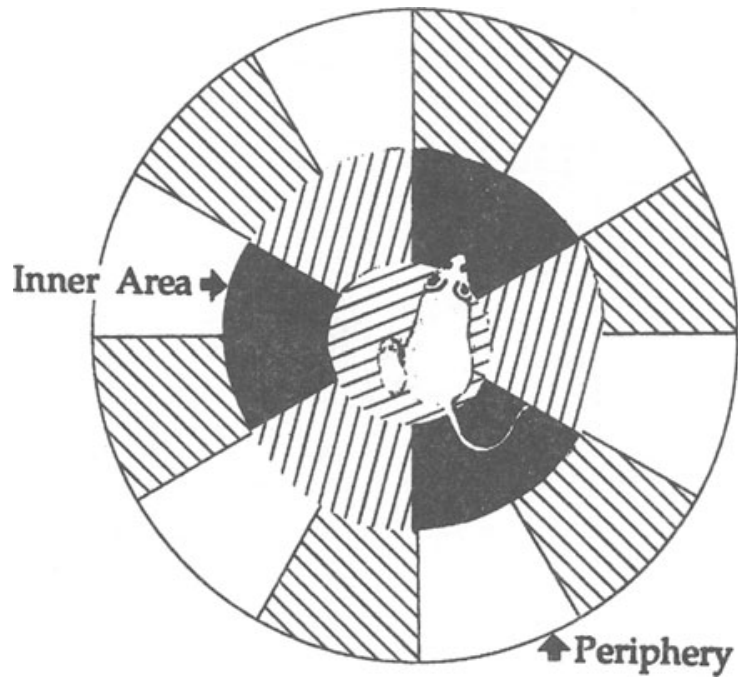

Figure 1. Center-placed adult mouse and newborn pup in a circular open field.

vent the subjects from following the odors left by other animals (Lagerspetz, 1964, p. 87). The reliability of the OF measurements was calculated by Broadhurst (1960) and was found to be .75 for ambulation.

\section{Procedure}

Ambulation denotes whole body movements from one OF unit to another and was recorded in accordance with our earlier research (Kvist \& Selander, 1992). The mature mouse was always placed in the OF center unit, after the inserted pup, with its tail in the direction of the experimenter. The adult animal's track was directly observed and manually recorded when it moved from one floor unit to another over a 2-min period (Kvist, 1985). When introduced into the experiment, the pup was placed either in the center unit or by the $\mathrm{OF}$ wall partition closest to the experimenter (Figure 1). The summed ambulatory scores include retrieving behavior.

Thigmotactic wall seeking signifies orientation toward the OF peripheral units but does not necessarily imply that the adult has bodily contact with the OF wall (Valle \& Bols, 1976). Seven center partitions delineated the two inner circles, and 12 OF units delineated the peripheral circle (Figure 1). The thigmotactic ratio - orientation to the periphery of the $\mathrm{OF}$ - was derived from the number of inner

Table 1

Experimental Animals and Days of Open-Field Recordings During Separate Reproductive Phases

\begin{tabular}{|c|c|c|c|c|c|c|c|c|c|}
\hline \multirow{3}{*}{$\begin{array}{l}\text { Reproductive } \\
\text { Phase }\end{array}$} & \multirow{3}{*}{$\begin{array}{c}\text { Day of } \\
\text { Experimentation }\end{array}$} & \multirow[b]{3}{*}{ Housing } & \multicolumn{3}{|c|}{ Females } & \multicolumn{3}{|c|}{ Males } & \multirow{3}{*}{$\begin{array}{c}\text { Testing } \\
\text { Days }\end{array}$} \\
\hline & & & \multirow[b]{2}{*}{$n$} & \multicolumn{2}{|c|}{ Weight } & \multirow[b]{2}{*}{$n$} & \multicolumn{2}{|c|}{ Weight } & \\
\hline & & & & $M$ & $S D$ & & $M$ & $S D$ & \\
\hline Baseline & $1-7$ & Isolated & 15 & & & 15 & & & 7 \\
\hline Mating & $7-8$ & Cohabited & 15 & & & 15 & & & 14 \\
\hline Gestation & $8-28$ & Family* & 7 & 27.5 & 1.0 & 7 & 32.7 & 3.0 & 6 \\
\hline Parturition & 28 & Single $\dagger$ & 8 & 27.4 & 2.0 & 8 & 32.1 & 2.0 & 6 \\
\hline Postpartum & $29-30$ & Family (+ pup) & 7 & & & 7 & & & 2 \\
\hline \multirow[t]{2}{*}{ (Pup test) } & & Single (+ pup) & 8 & & & & & & 2 \\
\hline & & Single (- pup) & & & & 8 & & & 2 \\
\hline \multirow[t]{3}{*}{ Lactation } & $31-39$ & Family (+ pup) & 7 & & & 7 & & & 9 \\
\hline & & Single (+ pup) & 8 & & & & & & 9 \\
\hline & & Single (- pup) & & & & 8 & & & 9 \\
\hline Unmated & $29-30$ & Isolated & 9 & 28.3 & 2.2 & 7 & 31.9 & 2.0 & 2 \\
\hline
\end{tabular}

Note-Weight is in grams. *Mother and father cohabited from mating until the end of the experimental period. †Mother and father separated 14 days after mating and remained alone throughout the experiment. 


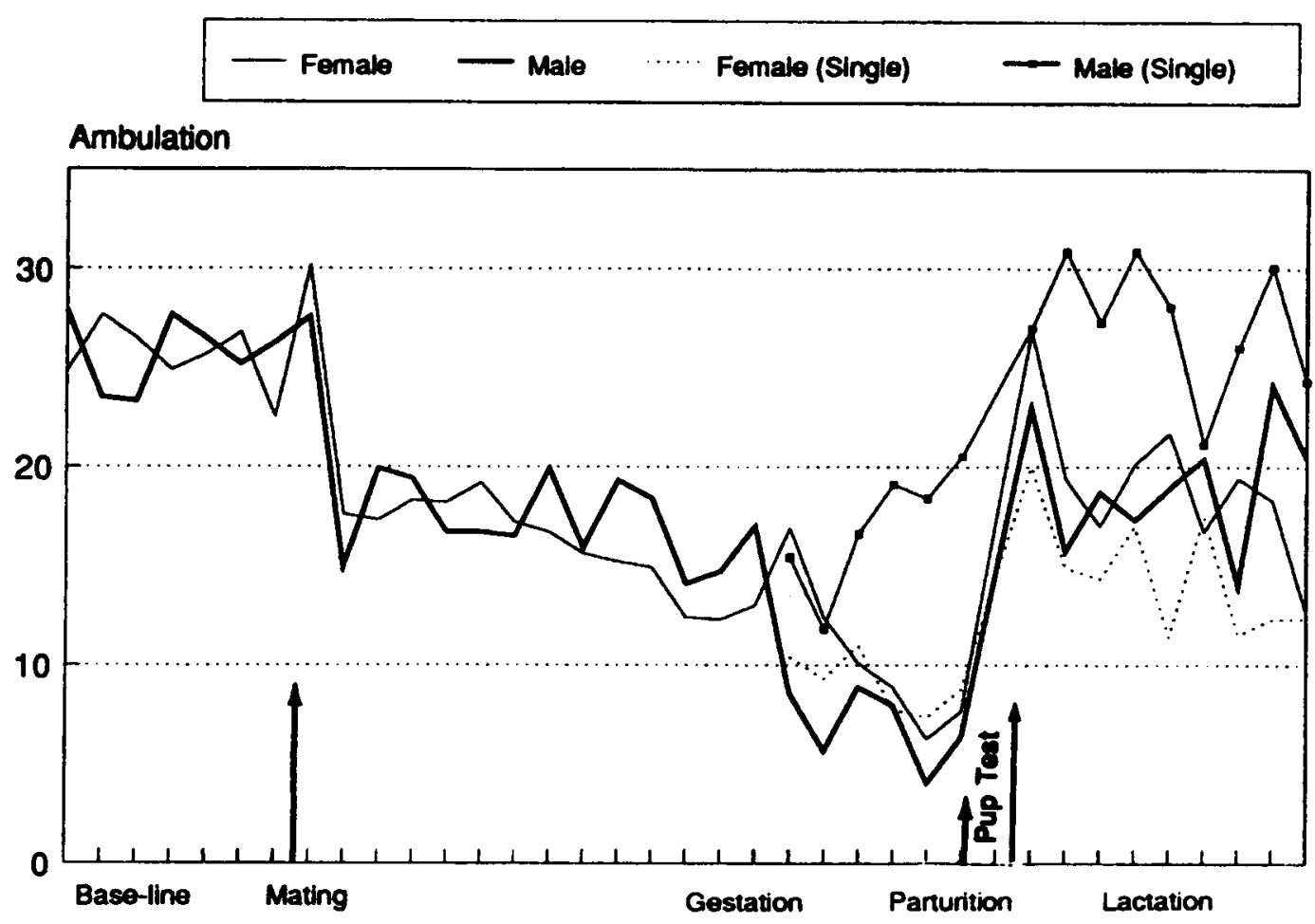

Figure 2. Ambulation (activity scores) recorded over 39 days for baseline, mating, gestation, and lactation. Pup test indicates the 2 days of experimentation with adult and newborn.

partitions entered divided by the sum of units visited by the mouse. Hence, the greater the ratio, the more prone the adult was to remain in the inner area.

Radial latency indicates the time in seconds (max., $120 \mathrm{sec}$ ) for the adult mouse to move from the OF center unit to a random peripheral unit.

Retrieval is the sum of OF units visited when the adult is carrying a newborn pup.

Pullus index signifies the number of times an adult mouse approaches the same OF partition where the newborn is located or an adjacent one divided by the total number of $O F$ units penetrated. This measure does not imply having bodily contact with the pup. The greater the ratio, the more prone the adult is to approaching the pup.

The main statistical method was analysis of variance (MANOVA, ANOVA [SPSS]). Post hoc $t$ tests and correlation coefficients were calculated to reduce the complexity of the design (WISTAT).

\section{RESULTS}

\section{OF Recordings Prepartum}

Baseline and mating. Figures 2,3 , and 4 show that the performance of female and male mice gave rise to sameshaped curves in ambulation, wall-seeking, and radial latency over a period of 3 weeks. However, both female and male mice decreased their ambulation from Day 7 to 21 $[t(28)=2.68, p<.01$ and $t(28)=3.21, p<.005$, respectively; see Figure 2]. Furthermore, females $[t(28)=1.75$, $p<.05]$ and males $[t(28)=2.61, p<.01]$ continuously displayed decreasing wall-seeking behavior during the mating period (Figure 3 ). On the other hand, no divergence from the baseline level in terms of radial latency was found between the sexes until Day 21 (Figure 4).

Gestation. On Day 22, when 8 males (Table 1) were removed from their female counterparts, these single males locomoted more than the other mice $[F(3,20)=15.02, p<$ $.01 ; t(13$ and 14$)=3.23$ and $6.75, p<.005$ and .0005$]$ and rereached their ambulatory baseline level on Day 28 . As regards ambulation from Day 7 to 28 , the other mice decreased their locomotion to about a third of their initial activity levels $[t(12$ and 14$)=3.51$ and $5.53, p<.005$ and $.0005]$.

From Day 22 to 28 , the last week of gestation, the family males differed from the other mice in terms of wall seeking and radial latency (Figures 3 and 4). The same males remained closest to the center starting point $[F(3,20)=$ $4.91, p<.05]$ and exhibited the maximum of radial latency registered $[F(3,20)=12.35, p<.01]$. Moreover, even the other animals enhanced their radial latency during this period $[t(12$ and 14$)=1.87$ and $3.67, p<.05$ and .001 ; Figure 4). Family females and males as well as single females occupied more center partitions continuously from Day 7 and 28 [ $t(12$ and 14$)=1.85$ and $2.20, p<.05$ and .025$]$.

\section{OF Recordings Postpartum}

OF recordings without newborn. At 2 days after parturition, all mice increased their ambulation $[F(3,32)=$ $22.20, p<.01]$. The single males ambulated more than both the family females and males as well as single females $[t(13$ and 14$)=4.84$ and $8.60, p<.0005]$. Still, on 


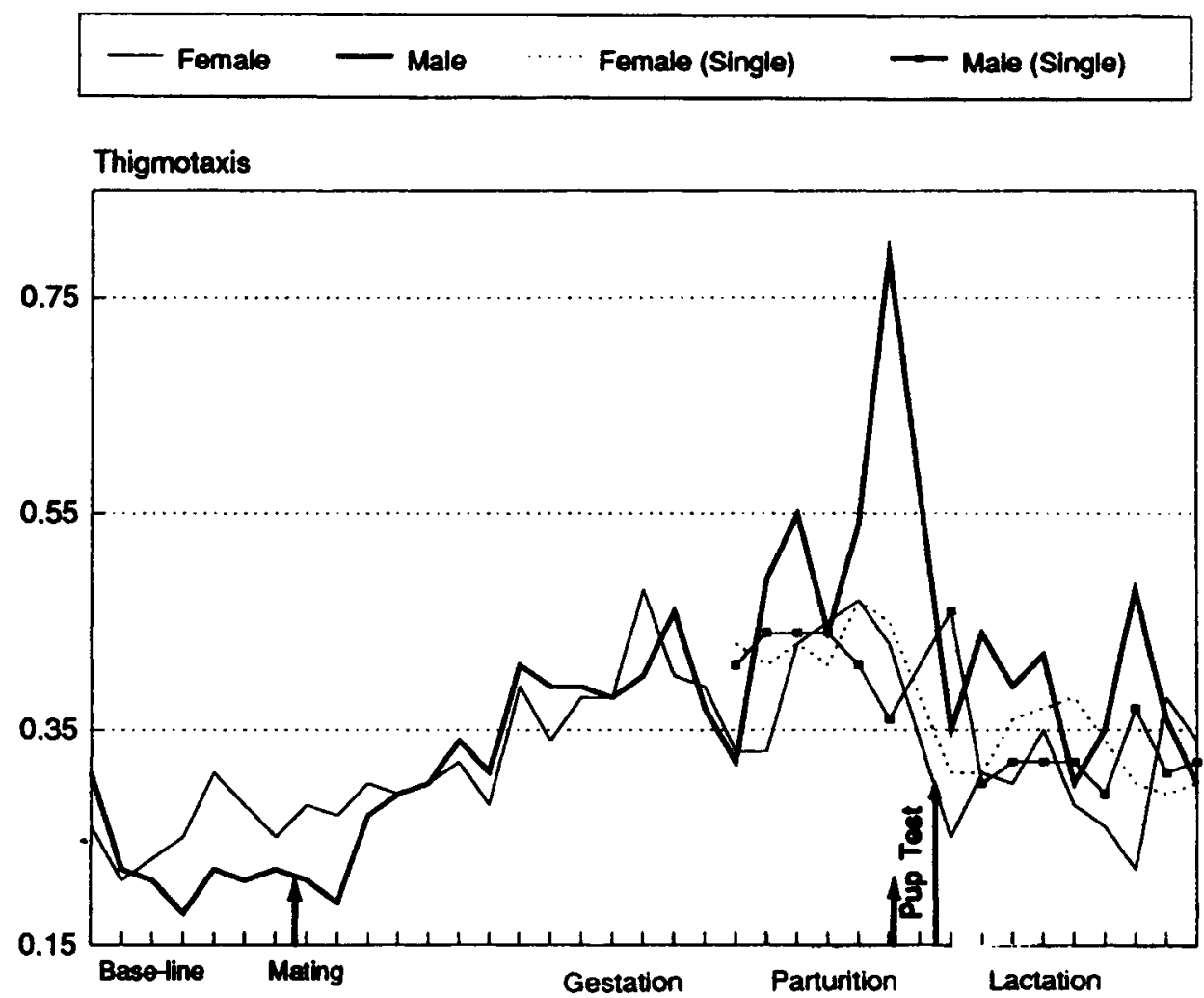

Figure 3. Thigmotaxis (ratio) during four phases pertaining to reproduction of mice. Pup test indicates the 2 days of experimentation with adult and newborn.

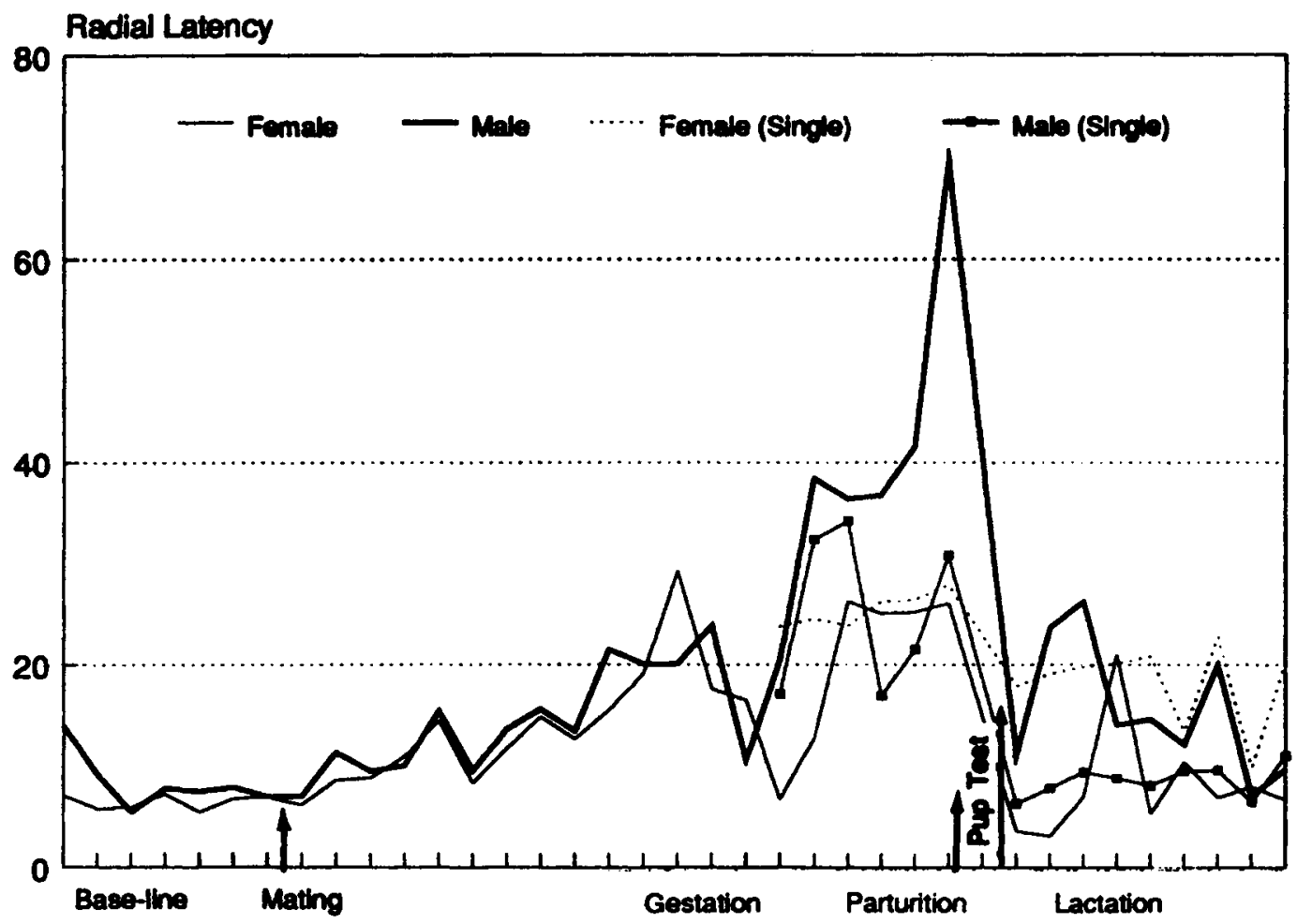

Figure 4. Curves depicting radial latency in seconds of the mice during the experimental period. Pup test indicates the 2 days of experimentation with adult and newborn. 
Table 2

Female and Male Open-Field Behavior Affected by the Pups' Presence and Position as Well as by Housing Conditions

\begin{tabular}{|c|c|c|c|c|c|c|c|}
\hline \multirow{2}{*}{$\begin{array}{c}\text { Independent } \\
\text { Variable }\end{array}$} & \multirow[b]{2}{*}{$d f$} & \multicolumn{2}{|c|}{ Ambulation } & \multicolumn{2}{|c|}{ Thigmotaxis } & \multicolumn{2}{|c|}{ Radial Latency } \\
\hline & & $F^{*}$ & $p$ & $F$ & $p$ & $F$ & $p$ \\
\hline \multicolumn{8}{|c|}{ All Females } \\
\hline Pup $\dagger$ & $(1,76)$ & 12.14 & .001 & 5.25 & .025 & 6.06 & .016 \\
\hline Position + & $(1,76)$ & 5.64 & .020 & 4.16 & .045 & & \\
\hline Housing§ & $(1,73)$ & & & 6.06 & .016 & 3.99 & .050 \\
\hline \multicolumn{8}{|c|}{ Family + Single Females } \\
\hline Pup & $(1,52)$ & 3.93 & .053 & & & & \\
\hline Position & $(1,52)$ & 5.57 & .022 & & & & \\
\hline Housing & $(1,52)$ & & & 6.14 & .016 & & \\
\hline \multicolumn{8}{|c|}{ Single + Virgin Females } \\
\hline Pup & $(1,46)$ & 14.20 & .000 & 4.23 & .045 & 4.30 & .044 \\
\hline Position & $(1,46)$ & & & 3.75 & .059 & & \\
\hline \multicolumn{8}{|c|}{ All Males } \\
\hline Pup & $(1,72)$ & 6.01 & .017 & & & & \\
\hline Position & $(1,72)$ & & & 4.04 & .048 & 12.89 & .001 \\
\hline Housing & $(1,73)$ & 26.72 & .000 & & & & \\
\hline \multicolumn{8}{|c|}{ Family + Single Males } \\
\hline Pup & $(1,52)$ & 5.36 & .025 & & & & \\
\hline Position & $(1,52)$ & & & & & 8.15 & .006 \\
\hline Housing & $(1,52)$ & 31.02 & .000 & 5.66 & .021 & & \\
\hline \multicolumn{8}{|c|}{ Single + Unmated Males } \\
\hline Pup & $(1,42)$ & 5.61 & .023 & & & & \\
\hline Position & $(1,42)$ & & & 3.88 & .056 & 10.35 & .002 \\
\hline
\end{tabular}

* $F$ value for the individual univariates. IIndicates whether it was her/his or a pup of another. †Signifies position of pup. §Housing explained in Table 1.

the last day of experimentation (Day 39), the females did not reach their initial activity levels $[t(12$ and 14$)=2.27$ and 2.55, $p<.025$ and .01; Figure 3). On the other hand, in terms of wall seeking and radial latency, all animals reached their initial ambulatory levels (Figures 3 and 4).

\section{Adult Pup-Induced OF Behavior}

Impact of pup's genetic origin. In the presence of their own pups, all mice displayed an increased level of ambulation, which was most clearly observed in the single females and family males. All animals exhibited a shorter radial latency induced by their own pups. An increase in wall-seeking behavior in the females was caused by the presence of their own pups (Tables 3-4). Regardless of the pups' genetic origin, females retrieved a newborn an average of $13.9(S D=8.1)$ times for a period of $2 \mathrm{~min}$; ambulation and retrieval correlated for both family females $[r(15)=.81]$ and single females $[r(15)=.90]$ at a level of $p<.01$. The males hardly retrieved newborn pups at all.

Effect of pup's OF position. When newborns were placed by the wall, all females ambulated more than in the case of center-placed pups. In the case of wall-positioned pups, females were also more wall seeking, in agreement with the behavior displayed by males, who in addition exhibited a shorter radial latency in this situation. The OF position of the pups was not decisive for the females' retrieval of the young.
Consequence of housing conditions. When familyhoused, both females and males altered their levels of ambulation according to the position of the newborn (Tables $2-4)$. When pups were placed by the wall external to the adults' center position, parental locomotion increased significantly. Virgin females, in turn, displayed increased wall seeking when the newborns remained by the wall (Tables $2-3)$. In general, nulliparous females ambulated less [ $t(14$ and 15$)=1.80$ and $2.76, p<.05$ and .01$]$ and were less wall seeking $[t(14$ and 15$)=1.89$ and $4.00, p<.05$ and $.001]$ than primiparous females.

Singly housed males had a shorter radial latency and kept closer to the newborns at their wall position. In general, these males ambulated more than family males $[t(13)=$ 2.01 to $5.37, p<.05$ to .0005 ]. Unmated males behaved as did single males (Tables 2 and 4). A comparison showed that unmated males ambulated by the pups' center position more $[t(12)=2.28, p<.025]$ than did family males, but did so less than single males $[t(13)=3.91, p<.01]$. Unmated males were more wall seeking when the pup was wall-positioned than were the other males [ $t(12$ and 13$)=$ 1.88 and $2.06, p<.05]$.

Pup-induced adult sex differences in OF-dependent parameters. It was indicated by means of MANOVA that females generally ambulated more $[F(1,144)=18.43$, $p=.00]$ and were more wall-seeking $[F(1,144)=6.85$, $p<.01]$ than males. Also interactions between the sex and 
Table 3

Significant Differences ( $t$ tests) in Female Open-Field Behavior

in Conjunction With Its Own or Another's Pup and Its

Open-Field Position as Well as With Its Parental Housing Conditions

\begin{tabular}{|c|c|c|c|c|c|c|c|c|c|c|}
\hline \multirow{2}{*}{$\begin{array}{l}\text { Independent } \\
\text { Variable }\end{array}$} & \multirow[b]{2}{*}{$d f$} & \multicolumn{3}{|c|}{ Ambulation } & \multicolumn{3}{|c|}{ Thigmotaxis } & \multicolumn{3}{|c|}{ Radial Latency } \\
\hline & & $M$ & $t$ & $p$ & $M$ & $t$ & $p$ & $M$ & $t$ & $p$ \\
\hline \multicolumn{11}{|c|}{ All Females } \\
\hline \multicolumn{11}{|l|}{ Pup } \\
\hline $\begin{array}{l}\text { Own } \\
\text { Another's }\end{array}$ & (76) & $\begin{array}{l}52.47 \\
30.40\end{array}$ & 3.48 & .0005 & $\begin{array}{l}.24 \\
.33\end{array}$ & 2.29 & .025 & $\begin{array}{r}6.00 \\
17.88\end{array}$ & 2.46 & .01 \\
\hline \multicolumn{11}{|c|}{ Position of Pup } \\
\hline Center & & 31.28 & 2.37 & .005 & .33 & 2.04 & .025 & & & \\
\hline Wall & & 46.49 & & & .25 & & & & & \\
\hline \multicolumn{11}{|c|}{ Family + Single Females } \\
\hline \multicolumn{11}{|l|}{ Pup } \\
\hline Own & $(58)$ & 52.47 & 2.04 & .05 & & & & & & \\
\hline Another's & & 36.87 & & & & & & & & \\
\hline \multicolumn{11}{|c|}{ Position of Pup } \\
\hline Center & & 35.90 & 2.32 & .025 & & & & & & \\
\hline Wall & & 53.53 & & & & & & & & \\
\hline \multicolumn{11}{|l|}{ Housing* } \\
\hline Family & & & & & .20 & 2.57 & .01 & 5.21 & 1.79 & .05 \\
\hline Single & & & & & .29 & & & 12.34 & & \\
\hline \multicolumn{11}{|c|}{ Family Females } \\
\hline \multicolumn{11}{|c|}{ Position of Pup } \\
\hline Center & (26) & 31.86 & 2.24 & .025 & & & & & & \\
\hline Wall & & 56.00 & & & & & & & & \\
\hline \multicolumn{11}{|c|}{ Single Females } \\
\hline \multicolumn{11}{|l|}{ Pup } \\
\hline Own & (30) & 55.50 & 1.93 & .05 & & & & & & \\
\hline Another's & & 35.31 & & & & & & & & \\
\hline \multicolumn{11}{|c|}{ Virgin Females } \\
\hline Position of $\mathrm{Pl}$ & & & & & & & & & & \\
\hline Center & (16) & & & & .57 & 3.32 & .005 & & & \\
\hline Wall & & & & & .30 & & & & & \\
\hline
\end{tabular}

*Housing explained in Table 1.

the origin of pup as regards ambulation $[F(1,144)=4.74$, $p=.03]$ and wall seeking $[F(1,144)=4.98, p<.03]$ were found to exist. Radial latency, on the other hand, did not differ significantly between adults of different sexes. As regards the pullus index, female groups exhibited a higher value on the whole $[t(18)=3.39, p<.005]$ than did male groups (Figure 5). A summary of significant sex differences in OF parameters recorded in the presence of a oneday old pup is presented in Table 5.

Pullus index. Figure 5 shows that an adult's willingness to remain close to the newborn becomes evident regardless of the genetic origin of the pup. The position of the pups was, on the other hand, decisive for the adult orientation displayed by virgin females. They remained closer to the pups by the center position $[t(16)=4.85, p<.0005]$. The family males oriented most to their young by their own pups' center placement $[t(26)=3.89, p<.0005]$. In addition, Figure 5 reveals significant sex differences as regards the pullus index.

\section{DISCUSSION}

It was indicated that a mouse's recognition of a 1- or 2day-old newborn's genetic origin was not decisive for an adult's OF behavior. However, the initial distance between the field locations of a male and a newborn pup affected paternal OF behavior. Furthermore, sex differences in pup-induced $\mathrm{OF}$ behavior were observed in sexually experienced animals. Pup-induced psychological arousal as a behaviorally activating affective and motivational process (Young, 1959) was clearly seen in the unsheltered, "dangerous" seminatural environment-the manually recorded OF- a fact that agrees with findings by Brown (1993). The advantage of the OF apparatus is reviewed by Walsh and Cummins (1976) and the importance of the direct observation is stressed by Makino, Kato, and Maes (1991).

The newborn's genetic origin was alluded to in increased rates of locomotion, displayed especially by the singly caged females and the family-housed males, more so in the presence of their biological than in that of unrelated 1-day-old progeny. These two kinds of responsible adults made the greatest investments in time, work, and risk in caretaking. In other words, the family-housed female tends to be less responsible and invests less in caring for the pups in the presence of the male (Elwood \& Broom, 1978). He adopts a "maternal state," which serves the purpose of maximizing the propagation of his own genes (Csermely \& Mai- 
Table 4

Significant Differences ( $t$ tests) in Male Open-Field Behavior in Conjunction With Its Own or Another's Pup and Its Open-Field Position as Well as With Its Parental Housing Conditions

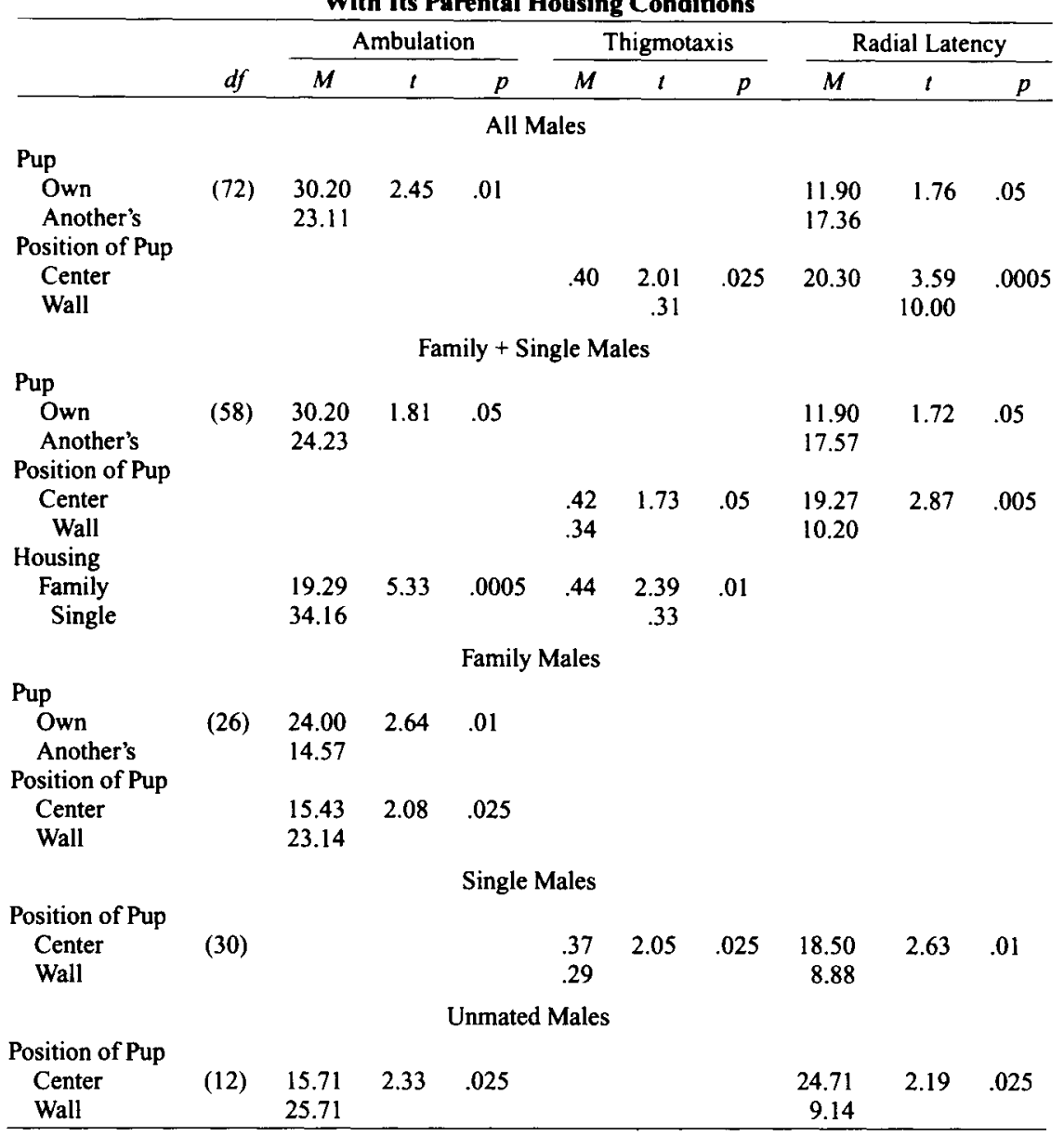

*Housing explained in Table 1.

Table 5

Summary of Significant Differences $(p<.05)$ Between

Female and Male Mice Under 10 Conditions

\begin{tabular}{|c|c|c|c|c|c|c|c|}
\hline $\begin{array}{c}\text { Housing } \\
\text { Condition }\end{array}$ & $\begin{array}{l}\text { Pup's } \\
\text { Origin }\end{array}$ & $\begin{array}{l}\text { Pup's OF } \\
\text { Position }\end{array}$ & Ambulation & $\begin{array}{c}\text { Wall } \\
\text { Seeking }\end{array}$ & $\begin{array}{c}\text { Radial } \\
\text { Latency }\end{array}$ & Retrieving & $\begin{array}{l}\text { Pullus } \\
\text { Index }\end{array}$ \\
\hline Family & own & center & + & + & - & + & \\
\hline Family & another's & center & + & & - & + & \\
\hline Single & own & center & & & - & + & + \\
\hline Single & another's & center & & + & - & + & + \\
\hline Virgin/unmated & another's & center & & - & & + & \\
\hline Family & own & wall & + & + & - & + & + \\
\hline Family & another's & wall & + & + & - & + & + \\
\hline Single & own & wall & + & & & + & \\
\hline Single & another's & wall & & & & + & + \\
\hline Virgin/unmated & another's & wall & & & & & + \\
\hline All & own & & + & + & - & + & + \\
\hline All & another's & & + & + & & + & + \\
\hline All & & center & + & + & - & + & + \\
\hline All & & wall & + & + & & + & + \\
\hline
\end{tabular}

Note- - F, open field; + , female greater than; - , female less than, male. 


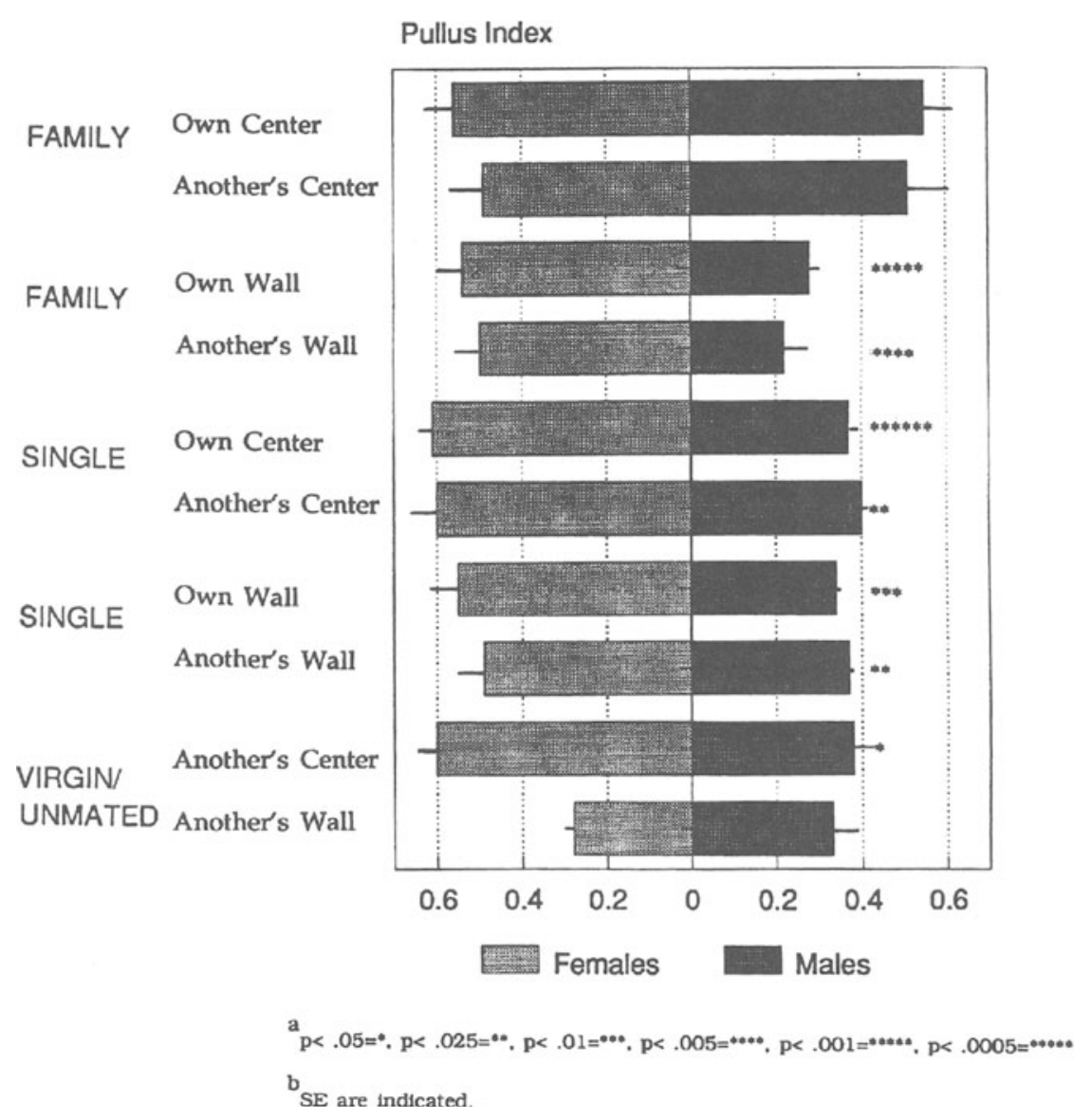

Figure 5. Pullus index signifies the number of times an adult mouse ambulates in the same or adjacent open-field unit of a pup, divided by the total sum of ambulatory scores. The index of the family females was higher than that of the family males by newborns' wall position by both their own $[t(12)=4.01, p<.001]$ and unrelated young $[t(12)=3.31, p<.005]$. The index of the single females always exceeded that of the single males by both center position of own $[t(14)=4.38, p<.0005]$ and unrelated newborn $[t(14)=2.54, p<.025]$ as well as by wall position of their own $[t(14)=2.92, p<.01]$ and unrelated pups $[t(14)=2.28, p<.025]$. Virgin females kept closer to pups than did unmated males $[t(14)=2.14, p<.05]$ by an unrelated newborn's center position.

nardi, 1981; Noirot, 1964b). Uncomplicated though it may be, the cost-benefit hypothesis (Csermely, 1991) does not explain why adult mice generally indiscriminately increase their OF locomotion in the presence of newborn pups. This reaction is most likely motivated by the positive affective value of pups' familiar attractants, such as ultrasounds (Noirot, 1964a, 1964b), olfactory cues, or preputial gland secretions (Brouette-Lahlou et al., 1991). According to Young (1959), affective processes are motivational in that they arouse, regulate, or activate behavior; for example, they urge the responsible adult to search for the litter. The cues emanating from an unrelated newborn are less effective because the adult lacks recognition of familiar positive affectional arousal. Support for the idea of an absence of factual genetic discrimination was further gained from observations that no preference was evident as regards wall-seeking, radial latency, or retrieving an animal's own versus an unre- lated pup. The latter finding was in agreement with results obtained by Csermely and Mainardi (1983). Additionally, the pullus index, revealing attraction to the newborn, did not expose any female or male selective response to biological or unrelated young. On the basis of our results, the adult's recognition of the offspring's genetic origin plays a minor role in the OF behavior recorded.

The pup's OF location was usually reflected in some of the recorded parameters decisive for an adult's orientation toward the newborn. When an adult is placed side by side with a center-positioned pup as opposed to one by the wall, a decreased ambulation is observed both in the two family parents and in unmated males. As regards wall-seeking, virgin females and single males penetrated more inner partitions with center-positioned newborn. Single and unmated males displayed a long radial latency, indicating pausing rather than freezing in the form of exploration of 
a new animate object (Kvist \& Selander, 1994). The importance of an offspring's OF position was further stressed by the pullus index of virgin females and family fathers. These kinds of rodents were occupied with the young when they were placed in the center OF unit in the immediate vicinity of the newborn. The virgin female's hesitation to move from her initial location can be interpreted as a fear response to an unfamiliar conspecific (Fleming \& Luebke, 1981), but the center-positioned family father moves only within the range of his home cage and does not look for a distant wall-located pup. Infant attractants are not efficient in arousing paternal behavior outside a home-cage-sized range (Mainardi et al., 1976). The initial distance between the adult and the newborn is decisive for paternal behavior.

Housing conditions influenced family females in the form of an enhanced occupation of inner OF partitions. The singly caged virgin females displayed the longest radial latencies, and the family-housed females, the shortest. In other words, female radial latency in the presence of a newborn correlates with the number of simultaneous cohabitants in the cage. Housing conditions affected gestational females' mates, which exhibited a similar ambulatory pattern to the females' in the form of steadily decreasing locomotion until parturition and by the adoption of a "maternal state" - in contrast to the singly caged males, which never became "maternal." In summation, family housing affects the OF behavior of the mice more than does single housing.

Sex differences are found in the presence of a newborn in sexually experienced animals. As a general rule, females ambulate more, are more wall seeking, have shorter radial latencies, retrieve more, and exhibit a higher pullus index than do males. Pups are potent reinforcers to the maternal rodents, regardless of how the animal becomes maternal (Fleming, Korsmit, \& Deller, 1994). In fact, the newborn is known as one of the strongest activating stimuli for an organism in a state of need and forces at least a pupdeprived female to exert herself to rescue and retrieve her litter more than to satisfy her own hunger, thirst, or sexual drives (see Bolles, 1967, p. 119).

As regards the pullus index, the advantage of the OF estimate is found in its power to reflect an adult's sensitivity to pup attractants or pup-induced psychological arousal. The benefit of the calculated value was especially evident in male mice that rarely retrieved and therefore, at first glance, appeared to lack interest in the newborn. As a general rule, the effectiveness of the pullus index has to be established outside the restricted space of the nest, and thus it is ideally recorded in a seminatural environment such as a manually recorded unsheltered OF (Brown, 1993).

The present findings demonstrated the importance of considering a registered individual-dependent $\mathrm{OF}$-dependent parameter, not in isolation but in light of changes in the other measured variables. Explaining the importance of the newborn's genetic origin solely on the basis of recorded ambulation, revealing the significance of the pup's OF position without indicating the distance between adult and offspring, emphasizing the meaning of housing conditions without taking into account adult sexual experience, interpreting sex differences without stressing the need state of an animal, and, finally, excluding the new estimate, the pullus index, would have created a superficial and erroneous picture of complex psychobiological dynamics.

\section{REFERENCES}

ADER, R., \& Belfer, M. L. (1962). Prenatal maternal anxiety and offspring emotionality in the rat. Psychological Reports, 10, 711 718.

AKUTA, T. (1979). Effects of rearing conditions on the behavior of mothers and on the later open-field behavior of the offspring in the mouse. Japanese Journal of Psychology, 50(2), 73-81.

BAUER, J. H. (1980). Social variables affect maternal behavior in lactating female hooded rats. Psychological Reports, 46, 1099-1104.

Bolles, R. C. (1967). Theory of motivation. Tokyo: John Weatherhill.

BRADLEY, E. (1969). Some effects of rearing young mice in the presence of adult male and female mice of the same strain. Papers in Psychology, 3(2), 61-62.

BroAdHurst, P. L. (1960). Experiments in psychogenetics. Applications of biometrical genetics to inheritance of behavior. In $\mathbf{H}$. J. Eysenck (Ed.), Experiments in personality (pp. 3-102). London: Routledge \& Kegan Paul.

Brouette-Lahlou, I., Vernet-Maury, E., \& Chanel, J. (1991). Is rat-dam licking behavior regulated by pups' preputial gland secretion? Animal learning \& Behavior, 19, 177-184.

Brown, R. E. (1993). Hormonal and experiential factors influencing parental behaviour in male rodents: An integrative approach. Behavioural Processes, 30, 1-28.

Csermely, D. (1980). Locomotor activity in newborn mice: I. Effect of paternal presence. Bolletino di Zoologia, 47, 139-142.

CSERmely, D. (1991). Patterns of parental care and their evolution in tetrapods. In G. Ghiara et al. (Eds.), Selected Symposia and Monographs U.Z.I. (Vol. 4, pp. 111-141). Modena, Italy: Mucchi.

CSERMELY, D., \& MaINARDi, D. (1981). Influence of social status on paternal behaviour in mice. Bolletino di Zoologia, 48, 183-189.

CSERmely, D., \& Mainardi, D. (1983). Infant signals. In A. Oliverio \& M. Zappella (Eds.), The behavior of human infants (pp. 1-19). New York: Plenum.

Elwood, R. W., \& Broom, D. M. (1978). The influence of litter size and parental behaviour on the development of Mongolian gerbil pups. $A n-$ imal Behaviour, 26, 438-454.

Fleming, A. S., \& LuebKe, C. (1981). Timidity prevents the virgin female rat from being a good mother: Emotionality differences between nulliparous and parturient females. Physiology \& Behavior, 27, 863868.

Fleming, A. S., Korsmit, M., \& Deller, M. (1994). Rat pups are potent reinforcers to the maternal animal: Effects of experience, parity, hormones, and dopamine function. Psychobiology, 22, 44-53.

Fullerton, C., \& Cowley, J. J. (1971). The differential effect of the presence of adult male and female mice on the growth and development of the young. Journal of Genetic Psychology, 119, 89-98.

HAYASHI, S., \& KimURA, T. (1978). Effects of exposure to males on sexual preference in female mice. Animal Behaviour, 26, 290-295.

KVIST, S. B. M. (1985). Open field activity after learning in mice (Reports from the Department of Psychology at Åbo Akademi: Monograph Suppl. 2). Turku, Finland: Åbo Akademis koperieringscentral.

KViST, S. B. M., \& Selander, R.-K. (1992). Maze-running and thigmotaxis in mice: Applicability of models across the sexes. Scandinavian Journal of Psychology, 33, 378-384.

Kvist, S. B. M., \& Selander, R.-K. (1994). Open-field thigmotaxis during various phases of the reproductive cycle. Scandinavian Journal of Psychology, 35, 220-229.

LAGERSPETZ, K. M. J. (1964). Studies on the aggressive behaviour of mice (Suomalaisen Tiedeakatemian Toimituksia. Annales Academiae Scientarium Fennicae: Series B, Vol. 131). Helsinki: Suomalainen Tiedeakatemia.

LagerspetZ, K. M. J., \& Heino, T. (1970). Changes in social reactions resulting from early experience with another species. Psychological Reports, 27, 255-262.

Lassalle, J. M., Bulman-Fleming, B., \& Wahlsten, D. (1991). Hybrid vigour and maternal environment in mice: II. Water escape learn- 
ing, open-field activity and spatial memory. Behavioural Processes, 23, 35-45.

Mainardi, D., Mainardi, M., Favoriti, M. P., \& Pasquali, A. (1976). A conflict behaviour in nursing female hamsters. Atti Societa ltaliana di Scienze Naturali e del Museo Civico di Storia Naturale in Milano, $117,59-68$.

MaKino, J., Kato, K., \& MaEs, F. W. (1991). Temporal structure of open field behavior in inbred strains of mice. Japanese Psychological Research, 33, 145-152.

MCCARTY, R., \& Southwick, C. H. (1977). Paternal care and the development of behavior in the southern grasshopper mouse, Onychomus torridus. Behavioral \& Neural Biology, 19, 476-490.

Mugford, R. A., \& NowelL, N. W. (1972). Paternal stimulation during infancy: Effect upon aggression and open-field performance of mice. Journal of Comparative \& Physiological Psychology, 79, 30-36.

NoIROT, E. (1964a). Changes in responsiveness to young in the adult mouse: I. The problematic effect of hormones. Animal Behaviour, 12, $52-58$
Nolrot, E. (1964b). Changes in responsiveness to young in the adult mouse: IV. The effect of an initial contact with a strong stimulus. $A n$ imal Behaviour, 12, 442-445.

VALLE, F. P., \& Bols, R. J. (1976). Age factors in sex differences in open-field activity of rats. Animal Learning \& Behavior, 4, 457-460.

WaLSH, R. N., \& Cummins, R. A. (1976). The open field test: A critical review. Psychological Bulletin, 83, 482-504.

WARD, R. (1980). Some effects of strain differences in maternal behavior of inbred mice. Developmental Psychobiology, 13, 181-190.

Wimer, R. E., \& Fuller, J. L. (1966). Pattern of behavior. In E. L. Green (Ed.), Biology of the laboratory mouse (pp. 629-653). London: McGraw-Hill.

YounG, P. T. (1959). The role of the affective processes in learning and motivation. Psychological Review, 66, 104-125.

(Manuscript received October 12, 1994; revision accepted for publication May 19, 1995.) 